\title{
The genome of the square archaeon Haloquadratum walsbyi : life at the limits of water activity
}

\author{
Henk Bolhuis*1, Peter Palm², Andy Wende ${ }^{2}$, Michaela Falb², \\ Markus Rampp ${ }^{3}$, Francisco Rodriguez-Valera ${ }^{4}$, Friedhelm Pfeiffer $^{2}$ and \\ Dieter Oesterhelt ${ }^{2}$
}

Address: ${ }^{1}$ Department of Microbial Ecology, Centre for Ecological and Evolutionary Studies, University of Groningen, The Netherlands, ${ }^{2}$ Department of Membrane Biochemistry, Max Planck Institute of Biochemistry, Martinsried, Germany, ${ }^{3}$ Computer Center of the Max-PlanckSociety, Max Planck Institute of Plasma Physics, Garching, Germany and ${ }^{4}$ Evolutionary Genomics Group and División de Microbiología, Universidad Miguel Hernandez, Alicante, Spain

Email: Henk Bolhuis* - h.bolhuis@rug.nl; Peter Palm - palm@biochem.mpg.de; Andy Wende - wende@biochem.mpg.de; Michaela Falb - falb@biochem.mpg.de; Markus Rampp - mjr@rzg.mpg.de; Francisco Rodriguez-Valera - frvalera@umh.es; Friedhelm Pfeiffer - fpf@ipp.mpg.de; Dieter Oesterhelt - oesterhe@biochem.mpg.de

* Corresponding author

Published: 04 July 2006

BMC Genomics 2006, 7:169 doi:10.1/86/147|-2164-7-169
Received: 17 March 2006

Accepted: 04 July 2006

This article is available from: http://www.biomedcentral.com/147/-2/64/7/169

(C) 2006 Bolhuis et al; licensee BioMed Central Ltd.

This is an Open Access article distributed under the terms of the Creative Commons Attribution License (http://creativecommons.org/licenses/by/2.0), which permits unrestricted use, distribution, and reproduction in any medium, provided the original work is properly cited.

\begin{abstract}
Background: The square halophilic archaeon Haloquadratum walsbyi dominates $\mathrm{NaCl}$-saturated and $\mathrm{MgCl}_{2}$ enriched aquatic ecosystems, which imposes a serious desiccation stress, caused by the extremely low water activity. The genome sequence was analyzed and physiological and physical experiments were carried out in order to reveal how $\mathrm{H}$. walsbyi has specialized into its narrow and hostile ecological niche and found ways to cope with the desiccation stress.
\end{abstract}

Results: A rich repertoire of proteins involved in phosphate metabolism, phototrophic growth and extracellular protective polymers, including the largest archaeal protein (9159 amino acids), a homolog to eukaryotic mucins, are amongst the most outstanding features. A relatively low GC content (47.9\%), 15-20\% less than in other halophilic archaea, and one of the lowest coding densities $(76.5 \%)$ known for prokaryotes might be an indication for the specialization in its unique environment

Conclusion: Although no direct genetic indication was found that can explain how this peculiar organism retains its square shape, the genome revealed several unique adaptive traits that allow this organism to thrive in its specific and extreme niche.

\section{Background}

Halophilic archaea (hereafter haloarchaea) predominate in $\mathrm{NaCl}$-saturated aquatic ecosystems in which the salinity increases up to about ten-times the average seawater concentration. Further concentration of thalassic (seawater derived) hypersaline environments leads to the precipita- tion of magnesium salts thereby forming the absolute limit for life, since magnesium saturated waters (bitterns) are devoid of active life [1]. And yet, up to this catastrophic event, haloarchaea are plentiful and reach population densities that rival the most productive natural aquatic environments known on Earth. Out of the more 
than 15 genera of haloarchaea, only one is responsible for the booming population explosion that follows the precipitation of $\mathrm{NaCl}$. Square, non-motile, pigmented archaea dominate in most thalassic NaCl-saturated environments, reaching population densities of over $10^{7}$ cells per $\mathrm{ml}$. The two unique features of these cells are the wafer like rectangular shape and a cell thickness of not more than $0.1 \mu \mathrm{m}$. Already known since the early $1980 \mathrm{~s}$ as Walsby's square bacterium [2], the organism resisted attempts to isolation for the next 25 years. However, in 2004, two strains of the square archaeon were independently isolated from a Spanish [3] and an Australian solar saltern [4]. In their specific habitat these squares are challenged by the sub-lethal conditions of an extremely high $\mathrm{MgCl}_{2}$ concentration and high solar irradiance. The hygroscopic properties of the divalent $\mathrm{Mg}^{2+}$ ions dramatically decrease the water activity $\left(A_{w}\right)$, a measure for the availability of free water molecules for biological processes $[5,6]$. The $A_{w}$ is 1.0 for pure water, 0.75 for a saturated $\mathrm{NaCl}$ solution and 0.3 for a saturated $\mathrm{MgCl}_{2}$ solution [7]. The actual $\mathrm{A}_{\mathrm{w}}$ of the $\mathrm{MgCl}_{2}$ enriched brines is unknown, but will decrease upon further concentration. Currently an Aw of 0.6 is recognized as the lower limit for life [6]. This means that although the organism thrives in an aqueous environment it suffers severe desiccation stress. Special mechanisms are therefore required to maintain optimal water activity within the cell and at the cell surface. Concomitant with the extremely high salinity, the amount of dissolved oxygen decreases to near anoxia and some essential nutrients (e.g. phosphates) become unavailable due to complexation with $\mathrm{Mg}^{2+}$. Here, we present features from the genome of Haloquadratum walsbyi that might explain the worldwide success of this organism in saturated brines.

\section{Results and discussion}

\section{H. walsbyi expresses a water enriched capsule}

The secret to the success of $H$. walsbyi in low water activity environments might rely in a remarkable convergence with metazoans and more specifically with mammals. This is provided by the most eye-catching gene in its genome, an over 27.000 nucleotides long gene encoding a 9.159 amino acid long protein, the largest archaeal protein known to date (Fig. 1). This giant protein, termed halomucin (Hmu1) is similar in amino acid sequence and domain organization (Fig. 1A) to animal mucins, which play an important role in protecting various tissues against desiccation (e.g. in bronchial epithelium and eyes) or harsh chemical conditions (e.g. in epithelia along the digestive tract) [8]. In function, mediating a specific adaptation to desiccation stress, halomucin resembles the mucous cocoon of lungfish that can escape dehydration for several years outside the water. The presence of an $\mathrm{N}$ terminal signal sequence suggests that this extremely large protein is translocated across the membrane, in accord- ance with a function outside the cell. Similar to animal mucins, halomucin contains domains that act as possible sites of glycosylation and sulfation which may further contribute to its overall negative charge, thereby creating an aqueous shield covering the cells. By means of Reverse Transcriptase PCR analysis, using primers specifically binding to various parts of the hmu1 mRNA, we could show that the gene is transcribed in full length (Fig. 1D). In addition, $H$. walsbyi encodes two 'smaller' proteins analogues to halomucin, termed Hmu2 (2885 aa) and Hmu3 (2079 aa), and at least 14 different S-layer glycoprotein homologs. Animal mucins may contain sialic acids which form rigid structures, capping the end of polysaccharide side chains of mucins. Although widespread in eukaryotes and some prokaryotes, sialic acids were not yet detected in archaea. H. walsbyi is probably able to synthesize sialic acid as it contains the two essential sialic acid biosynthesis genes neuA and neuB. Methanococcus jannaschii contains a gene encoding NeuB but lacks NeuA [9]. In addition to sialic acids, $H$. walsbyi can potentially also synthesize a poly-gamma-glutamate capsule by means of the bacterialtype poly-gamma-glutamate biosynthesis protein complex CapBCA [10]. Besides protection against desiccation, a cross-linked matrix of poly-gamma-glutamate may also contribute to the rigidity and maintenance of the unique square cell morphology of $H$. walsbyi.

\section{H. walsbyi encodes two bacteriorhodopsin proteins}

A consequence of the extremely high salinity is the decreased solubility of oxygen (about $20 \%$ of the amount of oxygen dissolved in freshwater). Low diffusion rates, relatively high temperatures, high oxygen consumption rates, and limited oxygenic photosynthesis leave the $\mathrm{NaCl}$-saturated brines virtually anoxic. Moreover, complexation of essential nutrients with the excessive amounts of cations imposes an additional problem in acquiring sufficient sources of energy, nutrients and trace elements. Oligotrophic microorganisms are well adapted to nutrient limitation, e.g. by increasing the surface to volume ratio thereby optimizing the nutrient uptake capacity relative to cell volume. Most oligotrophes achieve a high surface to volume ratio $(\mathrm{s} / \mathrm{v})$ by reducing their cell diameter; H. walsbyi does so by extremely flattening itself [11]. This strategy gives it what is probably the highest $\mathrm{s} / \mathrm{v}$ ratio within the microbial world. Whereas spherical shaped microorganisms have to remain small in order to retain an optimal s/ $\mathrm{v}$ ratio, the squares can become unlimitedly large since the $\mathrm{s} / \mathrm{v}$ ratio solely depends on their thickness which in nature always appears to be very low $(0.1-0.5 \mu \mathrm{m})$. In liquid cultures of $H$. walsbyi large cells of $40-40 \mu \mathrm{m}$ and larger have been observed [3]. In analogy to the oligotrophes, the high s/v ratio hints to a lifestyle in which membrane processes are of major importance. 
A

\section{Signal sequence}

$\operatorname{VGGL}(x)_{35}$ repeat

D/S-rich domain

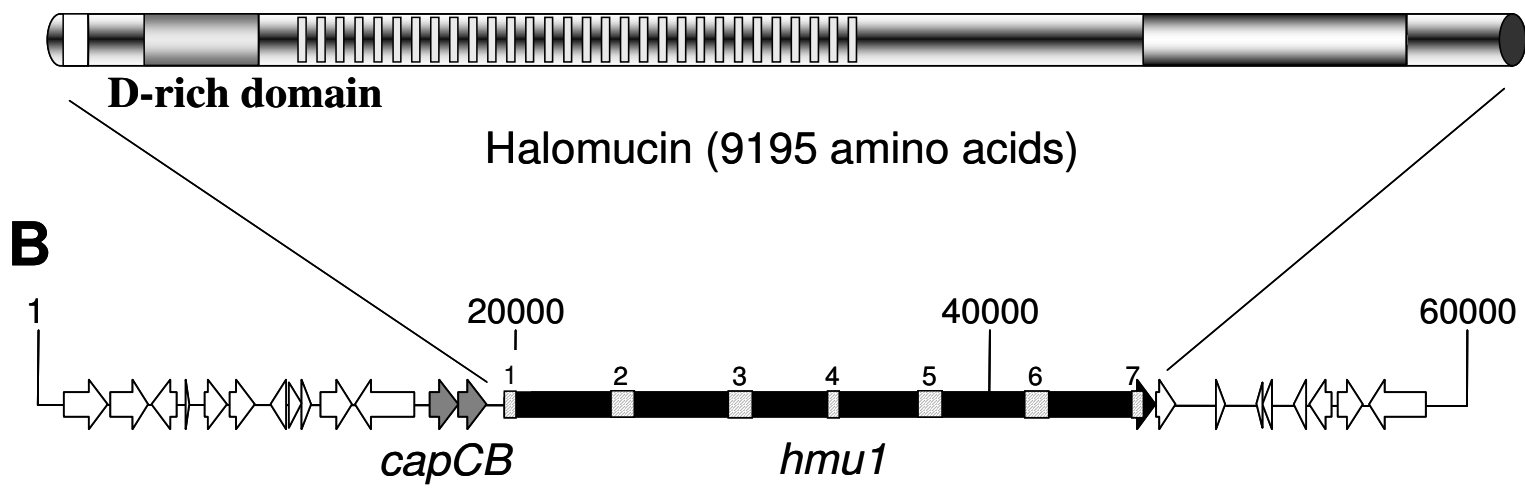

C

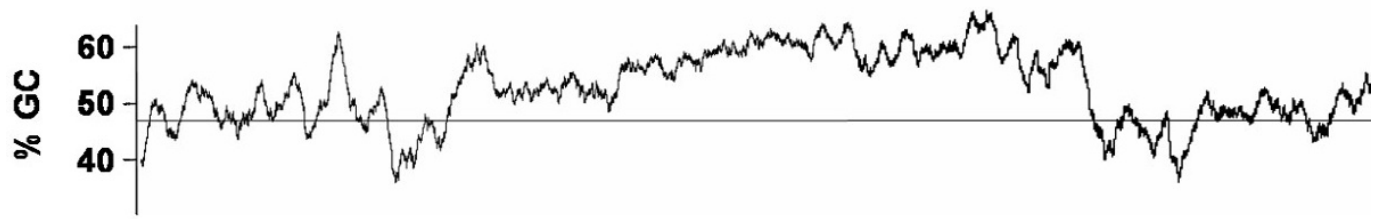

D

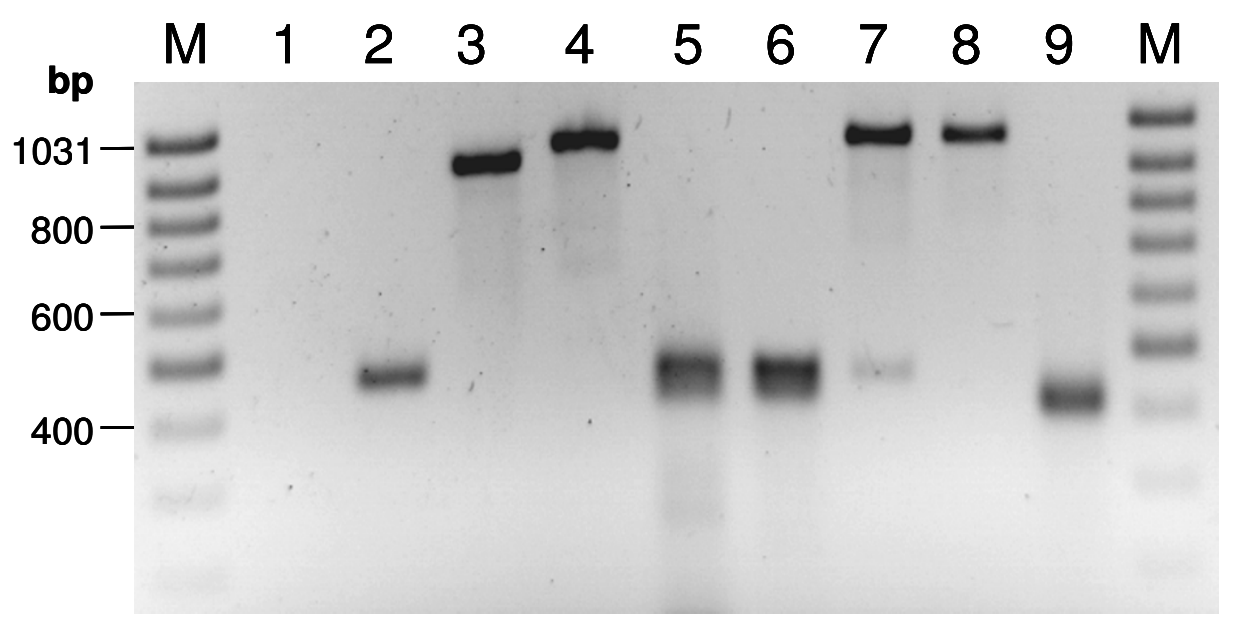

\section{Figure I}

H. walsbyi encodes halomucin, an extremely large protein homologous to mammalian mucins. GC content (C) and gene organization (B) of a 60.000 bp long region of the genome of $H$. walsbyi. This region contains the large, high GC gene encoding halomucin (hmul) and the two capsular protein biosynthesis genes capC and capB. The domain organization of halomucin (A) reveals domains typically found in mammalian mucins. The letters D, S, V, G, and L indicate domains enriched for the corresponding amino acids. Halomucin expression is shown by detection of its mRNA via RT-PCR (D). CDNA was prepared by reverse transcription using primer sets numbered I to 7 the position of which correspond to the striped and numbered boxes in the hmul gene (B). 

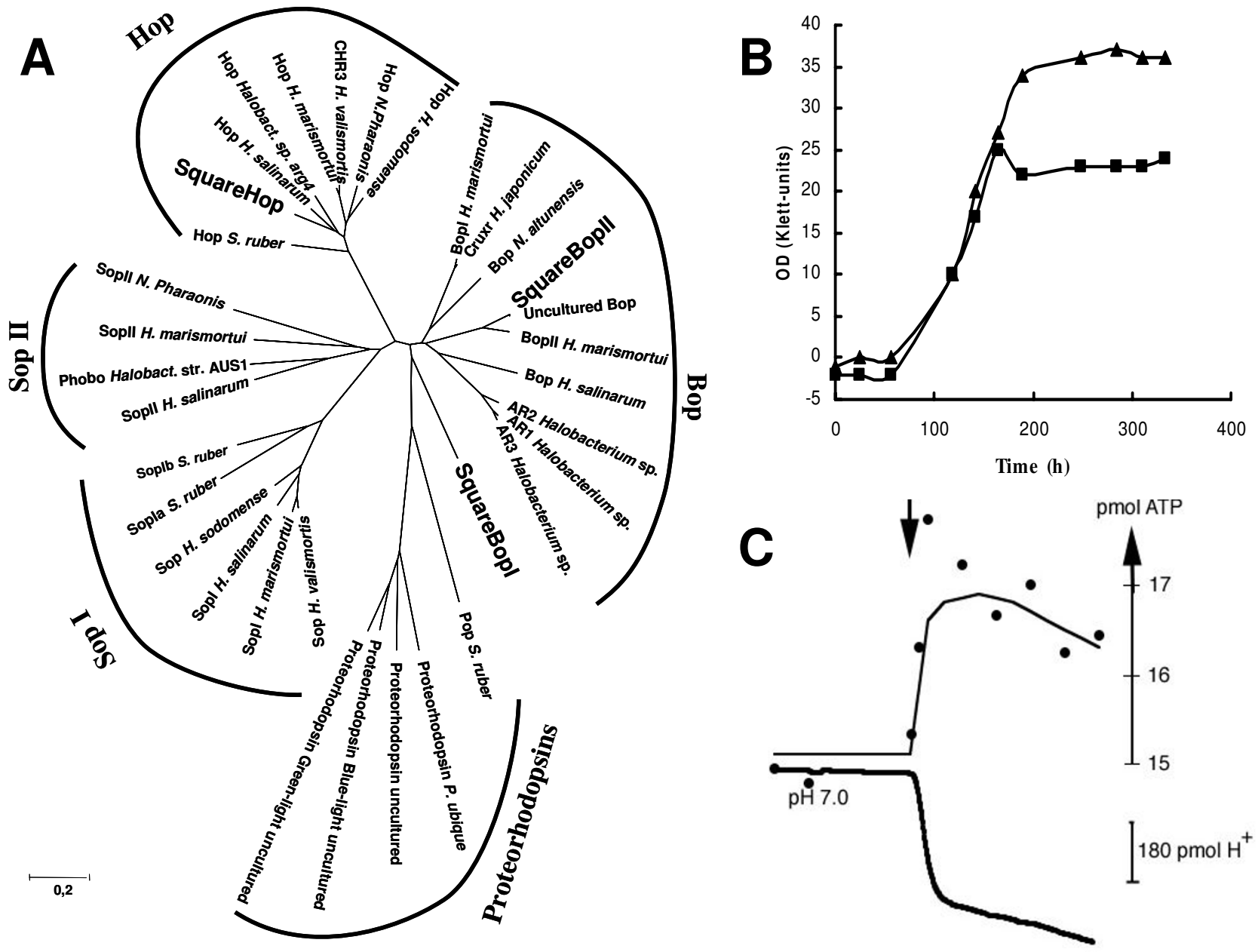

Figure 2

Phototrophic growth in $\boldsymbol{H}$. walsbyi. (A) Protein phylogenetic tree showing the position of the "opsin"-homologs encoded by $\mathrm{H}$. walsbyi, indicated as SquareBopl \& II and SquareHop for the proton pumping bacteriorhodopsins and chloride pumping halorhodopsin respectively. Trees were constructed with the neighbor-joining method using 1000 bootstrap replicates. Bop, bacteriorhodopsins; Hop, halorhodopsins; Sopl \& II; sensory-rhodopsins. (B) Phototrophic growth of aerobic $(\boldsymbol{A})$ and anaerobic $(\square)$ cultures of $H$. walsbyi incubated in the light. (C) Photo-phosphorylation in $H$. walsbyi measured through light induced ATP generation (upper curve) and proton $\left(\mathrm{H}^{+}\right)$extrusion (lower curve). Phylogenetic analysis was performed using the Microbial Genome Analysis System package MiGenAS [38,39].

Indeed, in addition to a set of normal haloarchaeal transporters (see gene-list in the supplementary material), $H$. walsbyi contains several unique ABC-type and major facilitator superfamily transporters that are not found in any of the other haloarchaea or in archaea in general. Amongst these are a TRAP-type C4-dicarboxylate transport system, 2 different ABC-type sulfonate transport systems and a phosphonate transport system (see below). An important process that is stimulated by the large membrane surface is the ability of $H$. walsbyi to grow phototrophically as shown in Figure 2. Only at a high s/v ratio the transmembrane protein bacteriorhodopsin, the responsible protein for phototrophic growth, can increase drastically in copy-number without taking away membrane space from other membrane components especially transport proteins and without affecting cell viability. Similar to solar panels, the ultra thin cells of $H$. walsbyi collect light as alternative energy source making optimally use of both sides of the membrane. The abundantly present gas vesicles, which are mainly located close to the cell periphery (Fig. 3), aid the cells to position themselves close and parallel to the surface. The well conserved haloarchaeal gas vesicle biosynthesis proteins are encoded by 12 genes located on two separate gene clusters 


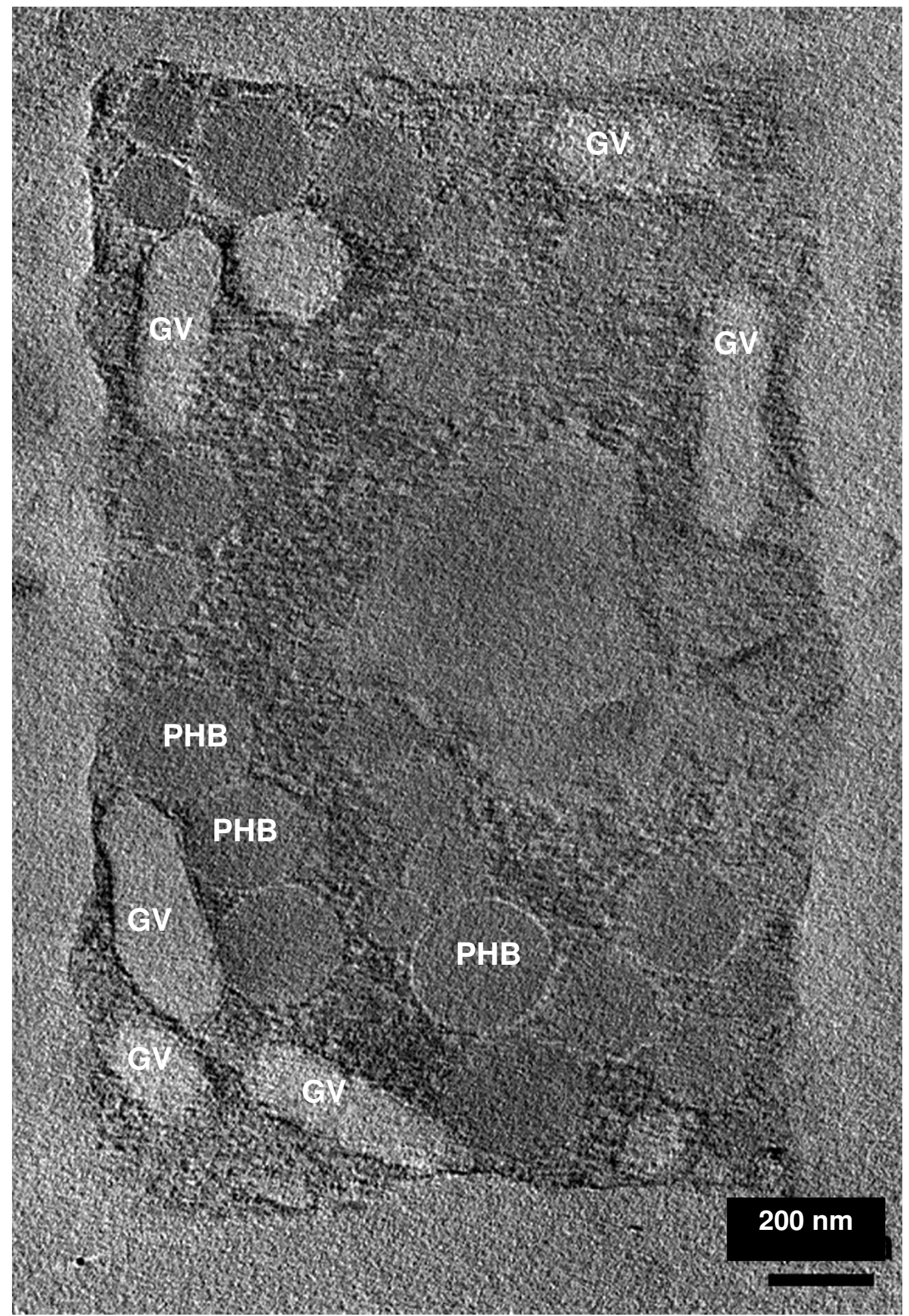

Figure 3

Electron Tomographic image of a single square cell of $\boldsymbol{H}$, walsbyi. In agreement with previous observations, gas vesicles (GV) recognized by their spindle shape are found at the borders of the cell. The large number of circular electron-dense bodies are most likely poly-3-hydroxy-butyric acid (PHB) polymers consistent with Nile-Blue staining patterns [4]. The genes encoding PHB biosynthesis proteins have been identified (image by $\mathrm{H}$. Engelhardt). 
gupACNO and gupFGHIJKLM. These clusters are separated by a $3.6 \mathrm{~kb}$ region containing several non-functional ISelement fragments and a ParA domain protein.

Three photoactive proteins are present, two proton pumping bacteriorhodopsins and one chloride pumping halorhodopsin. As expected, this non-motile organism lacks phototactic sensory rhodopsins as well as any flagellar or chemotactic protein. Both proton pumping rhodopsins, BopI and BopII, and the chloride pumping halorhodopsin contain all conserved amino acids essential for retinal binding and ion translocation. Phylogenetic analysis shows that BopI is positioned close to the root of the phylogenetic tree and might form a missing link to the eubacterial proteorhodopsins (Fig. 2). The genes encoding BopI and BopII are located very near to each other and close to the origin of replication, a fact that strengthens their importance for the biology of this organism. Interestingly, preliminary analysis of membrane protein expression patterns shows that BopI is amongst the most abundantly expressed membrane proteins (Fusetti and Poolman; unpublished results). Essential in the formation of functional rhodopsins is the synthesis of its chromophore retinal. Surprisingly, H. walsbyi encodes not less than three $\beta$ carotene mono-oxygenase homologs involved in the cleavage of beta-carotene yielding retinal [12], two of which are closely related to cyanobacterial $\beta$-carotene mono-oxygenases whereas the third is more similar to homologs in plants (Fig. 4). The recently sequenced genome of Haloarcula marismortui encodes a single $\beta$-carotene mono-oxygenase homolog on one of its plasmids [13], whereas no homologs of the $H$. walsbyi enzymes were found in the other phototrophic haloarchaea for which the protein responsible for $\beta$-carotene cleavage still remains to be identified.

\section{Phosphate metabolism in $\mathbf{H}$. walsbyi}

In the presence of a high $\mathrm{Mg}^{2+}$ concentration especially phosphates tend to form insoluble complexes and may become limiting for growth. Indeed, growth under phosphate limitation is reflected in a large number of exclusive traits found in the genome of $H$. walsbyi (Fig. 5). Unique amongst the archaea is the presence of a gene cluster that allows uptake of phosphonates and subsequent cleavage of the stable carbon-phosphorus bond by a phosphonate lyase. In various bacteria, phosphonate metabolism is known to be induced under phosphate limitation $[14,15]$. Moreover, phosphonates are ubiquitous in nature in the form of phosphonolipids and as side groups of polysaccharides and glycoproteins [15]. H. walsbyi also contains an operon encoding UDP-sulfoquinovose synthase (SqdB) plus two UDP-glucose 4-epimerase (GalE) homologs, key-enzymes in sulfolipid biosynthesis. Sulfolipids have been found to replace phospholipids in response to phosphate limitation in a number of photosynthetic bacteria and plants [16-18].

\section{H. walsbyi utilizes dihydroxyacetone via a phosphoenolpyruvate dependent phosphotransferase system}

Exceptional among archaea is the presence of a phosphoenolpyruvate (PEP) dependent phosphotransferase (PTS) system involved in the phosphorylation of dihydroxyacetone (DHA). PEP-PTS systems were so far only found in bacteria in which phosphorylation of substrates is coupled to their translocation over the membrane [19]. In many bacteria DHA is phosphorylated by an ATP dependent dihydroxyacetone kinase (DhaK). However, some bacteria and $H$. walsbyi contain a unique cytosolic PEPPTS dependent DhaK in which DHA is phosphorylated on the expense of PEP rather than ATP to give dihydroxyacetone-phosphate (DHAP) [20]. DHA is translocated over the membrane via facilitated diffusion, a process that is driven by its concentration gradient. Maintenance of an inwardly-directed DHA gradient is achieved by phosphorylation of DHA by the PTS system in the cytosol rather than by a membrane associated PTS system. DHAP can be used as substrate for gluconeogenesis or glycolysis. In the glycolytic reaction DHAP is converted back to PEP resulting in the net generation of one molecule of pyruvate and one molecule of ATP for each molecule of DHA taken up (Fig. 5). Recent experimentation showed that $H$. walsbyi can grow on DHA as carbon and energy source (data not shown). Alternatively, DHAP is also an important intermediate in the formation of the stereoisomer sn-glycerol1-phosphate which is part of the archaea-specific backbone of membrane lipids [21]. Interestingly, dihydroxyacetone is a putative overflow product of glycerol metabolism in Salinibacter ruber, the dominant bacterium in crystallizer ponds [22]. Metabolism of dihydroxyacetone by $H$. walsbyi might explain the observed synergistic effect on $H$. walsbyi colony formation when grown in association with $S$. ruber [3]. In addition to DHA, H. walsbyi can grow on glycerol and pyruvate [3] but also on amino acids [4] for which all biosynthesis pathways are completely present. Glycerol and pyruvate are probably taken up by diffusion since specific uptake systems have not been identified. For the amino acids a large repertoire of amino acid uptake systems are present.

\section{General genome properties}

The Genome of H. walsbyi strain HBSQ001, DSM 16790, comprises a 3,132,494 bp chromosome and a 46,867 bp plasmid and contains 2738 and 39 open reading frames (ORFS) respectively (Table 1 ). See [additional file 1] for a full list of proteins encoded by $H$. walsbyi. The base pair numbering of the genome was started approximately 50 nucleotides before the well conserved haloarchaeal region containing the origin of replication and the cell division 


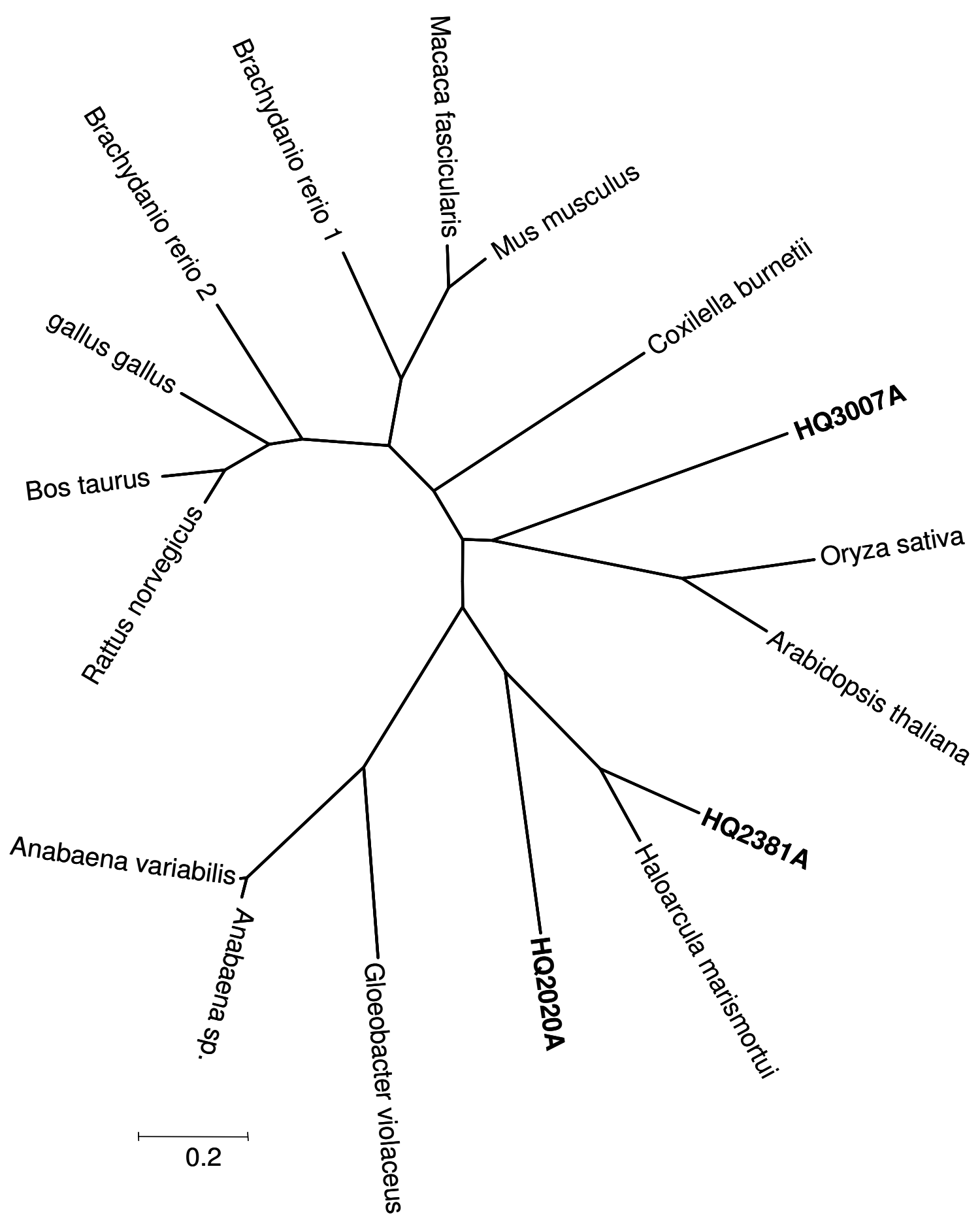

$\beta$-carotene mono-oxygenases

Figure 4

Phylogenetic tree showing the position of the three $\beta$-carotene 15, I5' mono-oxygenase homologs HQ2020A, HQ238 I A, HQ3007A of $H$. walsbyi. Trees were constructed with the neighbor-joining method using 1000 bootstrap replicates. 


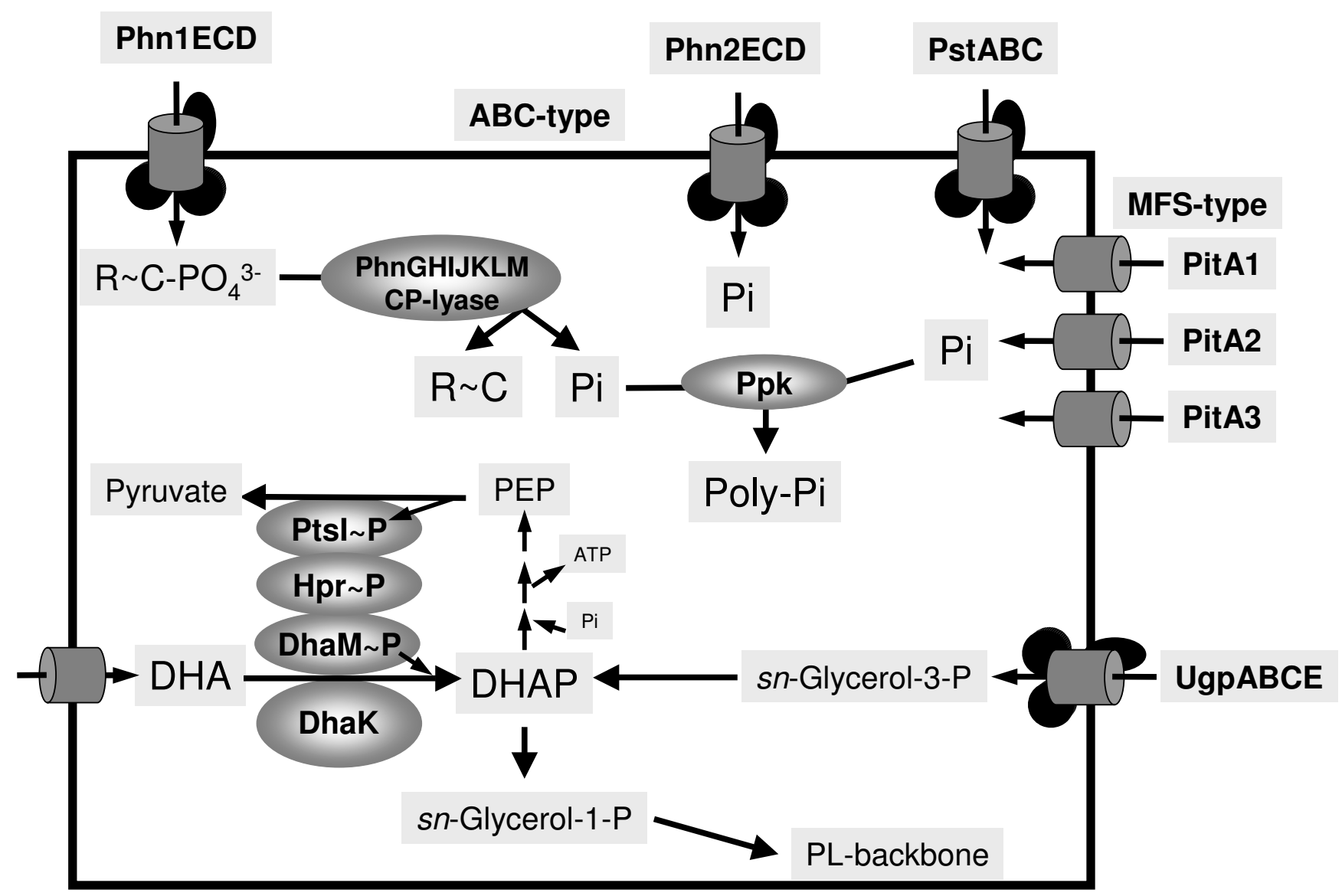

Figure 5

Phosphate metabolism in $\boldsymbol{H}$. walsbyi. Scheme revealing the proteins involved in phosphate metabolism. The transporters PitAl-3, Phn2ECD, PstABC and phosphate storage enzyme polyphosphate kinase (Ppk) are common in several haloarchaea. Unique to $H$. walsbyi are the bacterial-type proteins involved in phosphonate metabolism, an ABC-type phosphonate uptake system plus phosphonate lyase, and the PTS dependent dihydroxyacetone kinase (DHAK). DHA, dihydroxyacetone; DHAP, dihydroxyacetone phosphate; Pi, phosphate ion; PEP, phospho enolpyruvate; PL, phospholipid.

control protein CDC6_1 (HQ1001A) [23]. A striking feature of $H$. walsbyi's genome is a remarkably low GC content of $47.9 \%$ in contrast to the generally high GC content

Table I: General features of the $\boldsymbol{H}$. walsbyi genome

\begin{tabular}{lll}
\hline Feature & Chromosome & plasmid PL47 \\
\hline Replicon length (bp) & $3,132,494 \mathrm{bp}$ & $46,867 \mathrm{bp}$ \\
G+C content (\%) & $47.9 \%$ & $47.7 \%$ \\
G+C of transposases (\%) & $52 \%$ & - \\
Number of protein-coding genes & 2738 & 39 \\
Average size of proteins & 290 aa & 276 aa \\
Percentage coding for proteins or RNAs & $76.5 \%$ & $69.1 \%$ \\
Average gene distance & 289 & 371 \\
Number of rRNA operons (I6S, 23S, 5S) & 2 & - \\
Number of tRNAs & 43 & - \\
Number of other RNAs (7S, RNAseP) & 2 & - \\
Average pl of proteins & 5.1 & 5.2 \\
\end{tabular}

(60-70\% GC) of other haloarchaea. The GC content is constant over the genome with the exception of some GCrich islands that are highly enriched in transposases and phage related genes. The GC content of these transposases is similar to the GC content of transposases found in other haloarchaea (54\%) suggesting that they share a common pool of transposable elements and phages. The low GC content of the genome is intriguing since it is generally assumed that a high GC content is a specific adaptation of haloarchaea to the high levels of UV irradiation in the shallow coastal lagoons they inhabit. AT-rich genomes are more prone to UV induced thymidine dimer formation and possible accumulation of mutations than GC-rich genomes. In $H$. walsbyi this might partly be compensated by the large number of photolyases ( 4 copies). Despite the exceptional GC content, the majority of the typical haloarchaeal proteins encoded by $H$. walsbyi are highly conserved at the amino acid sequence level. Also the 


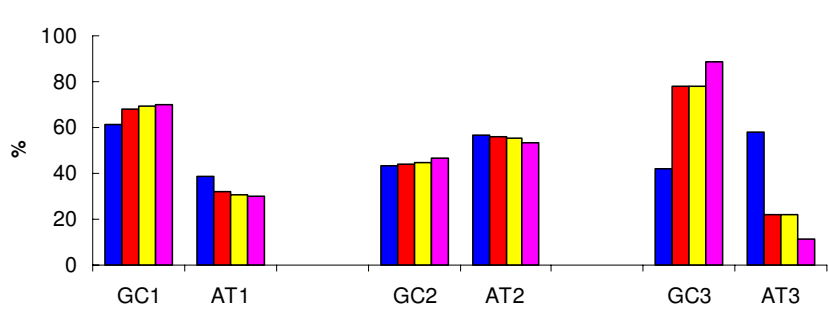

\section{Figure 6}

Codon usage in halophilic archaea. Indicated is the percentage of $\mathrm{G}$ plus $\mathrm{C}$ or $\mathrm{A}$ plus $\mathrm{T}$ at the different codon positions showing the large difference between $\mathrm{H}$. walsbyi and the other haloarchaea especially at the third codon position. Bars are $H$. walsbyi (blue), H. marismortui (red), N. pharaonis (yellow) and $H$. salinarum (purple).

characteristic overall high acidity of haloarchaeal proteins is well conserved in $H$. walsbyi (average pI = 5.1). As expected, $H$. walsbyi differs from the other haloarchaea mainly at the third codon position (Fig. 6). Conservation of amino acid sequence and restriction of GC deviation to the third codon position favor the hypothesis that $H$. walsbyi evolved from a 'normal' GC rich haloarchaeal ancestor rather than by convergent evolution from a non-related AT rich organism. A drift to an AT rich genome has been observed especially in organisms adapted to highly specialized niches such as endosymbionts [24] and the freeliving marine microorganisms Prochlorococcus sp. [25] and Pelagibacter ubique [26]. For two closely related species of Prochlorococcus that differ over $20 \%$ in overall GC content (30.8\% GC and 50.7\% GC) but less than 3\% at the 16S rDNA level it was argued that an enrichment in AT is a side effect of decreased selective pressure in a physically limited environment in which the low GC strains thrive. Mutational bias would increase the AT content by neutral drift. A lower GC content in the bacterial strains may be of advantage due to the slightly decreased demand for nitrogen, since guanine requires the incorporation of one additional nitrogen atom as compared to the other nucleotides $[25,26]$.

Similar to these microorganisms, H. walsbyi occupies a relatively stable but narrow ecological niche. However, nitrogen does not appear to be limiting in its natural habitat, and so we hypothesize that another factor, namely adaptation to the extremely high $\mathrm{MgCl} 2$ concentration, is responsible for the drift to an AT rich genome in H. walsbyi. Despite the presence of energy demanding cation efflux systems, the high external magnesium concentration will lead to an increase in the internal magnesium concentration that is higher than in other microorganisms. Magnesium ions are known to have a stabilizing effect on the DNA duplex, the secondary structure of RNA (Carter and Holbrook) and DNA-RNA heteroduplexes. In case of an already stable high-GC genome the additional stabilizing effect of magnesium might result in DNA rigidity that interferes with essential processes like DNA replication and transcription. We propose that the drift to an AT-rich genome might be induced as a long term evolutionary adaptation to this over-stabilization by magnesium and can be balanced by lowering the GC content of the genome.

\section{The genome of $\mathbf{H}$. walsbyi has a low coding density}

A related peculiarity of the $H$. walsbyi genome is its remarkably low coding density $(76 \%)$ as compared to other haloarchaea (86-91\%) and prokaryotes in general [27]. This is due to a very large average intergenic spacing of 289 bp mainly because of a high number of very long (> $1000 \mathrm{bp}$ ) intergenic regions. These long intergenic regions consist of non-coding DNA fragments, novel DNA repeat elements and pseudogenes, in most cases remnants of IS transposases. The low coding density, high number of pseudogenes and IS elements, and the drift towards a more AT rich genome may be signs that $H$. walsbyi is in a stage where it is undergoing genome shrinkage possibly due to its specialization into a very restrictive and specific environment with subsequent lack of growth competition from other species. Although saturated brines are present around the world and already exist since ancient geologic periods, competition with other microbes will be very relaxed in these physically limited environments, in a way similar to what happens with intracellular parasites or endosymbionts. The regular desiccation of these evaporative systems might act as evolutionary bottlenecks also favoring genome degradation [3].

\section{Description of the plasmid}

The $47 \mathrm{~kb}$ plasmid PL47 has a homogeneous GC distribution, is similar in GC content to the chromosome (Table 1 ) and contains thirty-nine open reading frames. Most genes are hypothetical or conserved hypothetical. Of the identified genes, the majority encode proteins involved in plasmid maintenance, replication and restriction modification with the majority being of bacterial or viral (phage) descent rather than of archaeal descent. Probably these proteins are dedicated to the replication and maintenance of the plasmid itself. However, the plasmid replication protein RepH is not encoded on the plasmid but is located on the main chromosome. In addition, the plasmid does not contain a homolog of the CDC6 cell division control protein that is commonly found on the smaller replicons of other haloarchaea. The gene coverage $(69 \%)$ of PL47 is even lower than that of the chromosome with an average gene distance of $371 \mathrm{bp}$. 


\section{Conclusion}

In addition to its eye-catching shape, the square archaeon $H$. walsbyi is in many ways unique amongst haloarchaea. Its genome revealed a broad range of novel adaptive traits in both genome composition and protein sequences that may have contributed to this organism's domination in saturated brines. Further functional studies are required to test these assumptions. Finally, these findings provide clues about how life is possible in the $5 \mathrm{M} \mathrm{MgCl}_{2}$ containing Discovery basin in the Mediterranean deep sea that was recently shown to contain a unique microbial community [28] and possibly even in the proposed brines at the surface of Jupiter's moons Europa and Ganymede.

\section{Methods}

\section{Cultivation, genome sequencing and assembly}

The Spanish isolate of the square halophilic archaeon Haloquadratum walsbyi strain HBSQ001 (DSM 16790) was grown to end exponential phase as described before [3]. $H$. walsbyi was sequenced with 6.5 -fold sequence coverage using a shotgun clone library (average insert size of $3 \mathrm{~kb}$ ), and assembled with the PHRED-PHRAP-CONSED package [29]. The sequence is of high quality (0.01 Errors/10 $\mathrm{kb})$.

\section{Gene prediction and annotation}

For gene prediction, REGANOR [30] from the annotation package GENDB [31] was used, which integrates results from CRITICA [32] and GLIMMER [33]. The automatically predicted ORF set (3013 ORFs) was expert-curated resulting in a theoretical proteome of 2777 proteins. Curation involved sequence comparison to proteins from other halophiles (Halobacterium salinarum strain R1, [34]), Natronomonas pharaonis [35], Haloarcula marismortui [13] and public protein sequence databases. This permitted to identify additional small proteins and to improve the correctness of start codon assignments. tRNAs and other RNAs were predicted using tRNAscan [36] and BLAST [37] against other halophiles, respectively. Phylogenetic analysis of proteins was performed using the Microbial Genome Analysis System package MiGenAS $[38,39]$ and the MEGA3 phylogenetic tool software package $[40,41]$.

\section{General genome properties}

The genome can be accessed via HaloLex [34]. General features and statistics on the genome of $\mathrm{H}$. walsbyi are shown in Table S1. The main origin of replication is located in a highly conserved region and consists of a conserved stem-loop structure, and open reading frames encoding the conserved CDC6 cell division control protein, a signal sequence peptidase and DNA polymerase B [42]. The sequence has been submitted to EMBL under the accession numbers [EMBL:AM180088, EMBL:AM180089] for the genome and plasmid PL47 respectively.

\section{Extraction of total RNA and DNase I digestion}

The RNA was extracted with peqGold RNAPure extraction solution (Peqlab Biotechnology) following the manufacturers instructions. After dissolving RNA in DEPC- $\mathrm{H}_{2} \mathrm{O}$ residual DNA was digested using the "DNA-free" kit (Ambion) following the manufacturers instructions. The quality of the RNA was checked using the 2100 Bioanalyzer (Agilent) and the RNA Nano LabChip (Agilent).

\section{cDNA synthesis}

Total RNA was reverse transcribed into cDNA using SuperScript II (Invitrogen) following the manufacturer's instructions with $2 \mu \mathrm{g}$ total RNA per reaction as template and the gene specific primers pcr4-rev and pcr7-rev, respectively.

\section{PCR reactions}

The PCR reactions were performed using HotStarTaq (Qiagen) ( $50 \mu \mathrm{l}$ per reaction) and $0.5 \mu \mathrm{l}$ of the cDNA samples as template. The following temperature profile was applied on a Thermocycler T3 (Biometra): $95^{\circ} \mathrm{C} 15 \mathrm{~min}$; $40 \times\left(95^{\circ} \mathrm{C} 30 \mathrm{sec}, 60^{\circ} \mathrm{C} 30 \mathrm{sec}, 72^{\circ} \mathrm{C} 50 \mathrm{sec}(500 \mathrm{bp}-\right.$ PCRs) or $90 \mathrm{sec}$ (1 kbp-PCRs). Subsequently the PCR reactions were analyzed by standard agarose gel electrophoresis.

\section{Primer sequences}

pcr1-for: 5'-CAT TGG ATC GGT GTC TGC ACA GCA AC-3'

pcr1-rev: 5'-GCG CCG CTT GAA GGA GTT ATT TGC G-3'

pcr2-for: 5'-GAT CAC GCT CGA CGA CCT CG-3'

pcr2-rev: 5'-CGT TGA TGA CGC CAG CCT GC-3'

pcr3-for: 5'-CCA CTG GTC AGG TGA ATG CCT C-3'

pcr3-rev: 5'-CTT CCT GTC GCA TCC GAC TGG-3'

pcr4-for: 5'-GAC GCT ACT GCC ACC GGC GAT G-3'

pcr4-rev: 5'-GCA GAC CCG TGT TCG AAC CGT CC-3'

pcr5-for: 5'-GGA CTT GCT GGC ACG ATC GAC-3'

pcr5-rev: 5'-CTC CAG ATG TGC CAA CCT CGC-3'

pcr6-for: 5'-GCG GTT GAG TGG TAT CTT CAC C-3'

pcr6-rev: 5'-GCT ATC GGT GGC GGT GTC G-3'

pcr7-for: 5'-CTC CCC ATC CAG TAG TCG GTC ATT GG-3'

pcr7-rev: 5'-GAT TGT ATC CTC TCA AAT GCC CCG CTA AG-3' 


\section{Authors' contributions}

Shotgun library preparation and sequencing was performed by PP. MF and FP provided genome assembly, initial ORF prediction and bioinformatics tools integrated into the HaloLex system and performed the genome statistics. AW performed the mRNA detection study of Halomucin. MR programmed and supported the genome analysis system MIGENAS and supported genome annotation. HB supervised the study, performed the manual annotation and wrote the manuscript jointly with FRV, FP and DO.

\section{Additional material}

\section{Additional file 1}

complete list of $\mathrm{H}$. walsbyi proteins. List of all Haloquadratum proteins ordered by function category and function class.

Click here for file

[http://www.biomedcentral.com/content/supplementary/1471-

2164-7-169-S1.doc]

\section{Acknowledgements}

We thank A. Mira and B. Poolman for critical reading the manuscript and helpful discussions, B-A Legault for support with phylogenetic analysis, $\mathrm{H}$. Engelhardt for the electron tomographic image and R. Brouwer, T. Gillich, F. Schoetz, V. Hickmann for additional bioinformatics support and S. von Gronau for technical assistance. This work was supported by a grant to H.B. from the Netherlands Organization of Science NWO/ALW/NPP85I.20.023, and a grant from the GEMINI project QLK3-CT-2002-02056.

\section{References}

I. Oren A: Diversity of halophilic microorganisms: Environments, phylogeny, physiology, and applications. Journal of Industrial Microbiology \& Biotechnology 2002, 28:56-63.

2. Walsby AE: A Square Bacterium. Nature 1980, 283:69-7I.

3. Bolhuis H, Poele EM, Rodriguez-Valera F: Isolation and cultivation of Walsby's square archaeon. Environ Microbiol 2004, 6:|287-|29|.

4. Burns DG, Camakaris HM, Janssen PH, Dyall-Smith ML: Cultivation of Walsby's square haloarchaeon. FEMS Microbiol Lett 2004, 238:469-473.

5. Galinski EA, Truper HG: Microbial behaviour in salt-stressed ecosystems. FEMS Microbiology Reviews 1994, 15:95-108.

6. Grant WD: Life at low water activity. Philos Trans $R$ Soc Lond $B$ Biol Sci 2004, 359: 1249-1266.

7. $\mathrm{Ha} \mathrm{Z}$, Chan CK: The water activities of $\mathbf{M g C l} 2, \mathbf{M g}(\mathrm{NO} 3) 2$, MgSO4 and their mixtures. Aerosol Science and Technology 1999 , 31:154-169.

8. Hollingsworth MA, Swanson BJ: Mucins in cancer: protection and control of the cell surface. Nat Rev Cancer 2004, 4:45-60.

9. Angata $T$, Varki $A$ : Chemical diversity in the sialic acids and related alpha-keto acids: an evolutionary perspective. Chem Rev 2002, 102:439-469.

10. Ashiuchi M, Misono $\mathrm{H}$ : Biochemistry and molecular genetics of poly-gamma-glutamate synthesis. Appl Microbiol Biotechnol 2002, 59:9-14.

II. Bolhuis H: Walsby's square archaeon; it's hip to be square but even more hip to be culturable. In Adaptation to life at high salt concentrations in archaea, bacteria and eukarya. Springer; 2005.

12. Ruch S, Beyer P, Ernst H, Al-Babili S: Retinal biosynthesis in Eubacteria: in vitro characterization of a novel carotenoid oxygenase from Synechocystis sp. PCC 6803. Mol Microbiol 2005, 55:1015-1024.
13. Baliga NS, Bonneau R, Facciotti MT, Pan M, Glusman G, Deutsch EW Shannon P, Chiu Y, Weng RS, Gan RR, Hung P, Date SV, Marcotte E, Hood L, Ng WV: Genome sequence of Haloarcula marismortui: a halophilic archaeon from the Dead Sea. Genome Res 2004, I 4:222I-2234.

14. Mendz GL, Megraud F, Korolik V: Phosphonate catabolism by Campylobacter spp. Arch Microbiol 2005, I 83: I I3-I 20.

15. White AK, Metcalf WW: Two C-P lyase operons in Pseudomonas stutzeri and their roles in the oxidation of phosphonates, phosphite, and hypophosphite. J Bacteriol 2004, 186:4730-4739.

16. Benning C, Beatty IT, Prince RC, Somerville CR: The sulfolipid sulfoquinovosyldiacylglycerol is not required for photosynthetic electron transport in Rhodobacter sphaeroides but enhances growth under phosphate limitation. Proc Natl Acad Sci U S A 1993, 90:1561-1565.

17. Yu B, Xu C, Benning C: Arabidopsis disrupted in SQD2 encoding sulfolipid synthase is impaired in phosphate-limited growth. Proc Natl Acad Sci U S A 2002, 99:5732-5737.

18. Aoki M, Sato N, Meguro A, Tsuzuki M: Differing involvement of sulfoquinovosyl diacylglycerol in photosystem II in two species of unicellular cyanobacteria. Eur J Biochem 2004, 271:685-693.

19. Kotrba P, Inui M, Yukawa H: Bacterial phosphotransferase system (PTS) in carbohydrate uptake and control of carbon metabolism. J Biosci Bioeng 200I, 92:502-5I7.

20. Gutknecht R, Beutler R, Garcia-Alles LF, Baumann U, Erni B: The dihydroxyacetone kinase of Escherichia coli utilizes a phosphoprotein instead of ATP as phosphoryl donor. EMBO J 200 I, 20:2480-2486.

21. Nishihara M, Yamazaki T, Oshima T, Koga Y: sn-glycerol-I-phosphate-forming activities in Archaea: separation of archaeal phospholipid biosynthesis and glycerol catabolism by glycerophosphate enantiomers. J Bacteriol 1999, 181:1330-1333.

22. Mongodin EF, Nelson KE, Daugherty S, Deboy RT, Wister J, Khouri H, Weidman J, Walsh DA, Papke RT, Sanchez PG, Sharma AK, Nesbo CL, Macleod D, Bapteste E, Doolittle WF, Charlebois RL, Legault B, Rodriguez-Valera F: The genome of Salinibacter ruber: Convergence and gene exchange among hyperhalophilic bacteria and archaea. Proc Natl Acad Sci U S A 2005, 102:18|47-18152.

23. Berquist BR, Dassarma S: An archaeal chromosomal autonomously replicating sequence element from an extreme halophile, Halobacterium sp. strain NRC-I. J Bacteriol 2003, 185:5959-5966

24. Moran NA, Plague GR: Genomic changes following host restriction in bacteria. Curr Opin Genet Dev 2004, 14:627-633.

25. Dufresne A, Garczarek L, Partensky F: Accelerated evolution associated with genome reduction in a free-living prokaryote. Genome Biol 2005, 6:R I4.

26. Giovannoni SJ, Tripp HJ, Givan S, Podar M, Vergin KL, Baptista D, Bibbs L, Eads J, Richardson TH, Noordewier M, Rappe MS, Short JM, Carrington JC, Mathur EJ: Genome streamlining in a cosmopolitan oceanic bacterium. Science 2005, 309:1242-1245.

27. Mira A, Ochman H, Moran NA: Deletional bias and the evolution of bacterial genomes. Trends Genet 200I, 17:589-596.

28. van der Wielen PWJJ, Bolhuis $\mathrm{H}$, Borin S, Daffonchio D, Corselli C Giuliano L, D'Auria G, de Lange GJ, Huebner A, Varnavas SP, Thomson J, Tamburini C, Marty D, McGenity TJ, Timmis KN, BioDeep SP: The Enigma of Prokaryotic Life in Deep Hypersaline Anoxic Basins. Science 2005, 307:121-123.

29. Gordon D, Abajian C, Green P: Consed: a graphical tool for sequence finishing. Genome Res 1998, 8:195-202.

30. McHardy AC, Goesmann A, Puhler A, Meyer F: Development of joint application strategies for two microbial gene finders. Bioinformatics 2004, 20:1622-1631.

31. Meyer F, Goesmann A, McHardy AC, Bartels D, Bekel T, Clausen J, Kalinowski J, Linke B, Rupp O, Giegerich R, Puhler A: GenDB--an open source genome annotation system for prokaryote genomes. Nucleic Acids Res 2003, 31:2 187-2195.

32. Badger $\mathrm{JH}$, Olsen $\mathrm{G}$ : CRITICA: coding region identification tool invoking comparative analysis. Mol Biol Evol 1999, 16:512-524.

33. Delcher AL, Harmon D, Kasif S, White O, Salzberg SL: Improved microbial gene identification with GLIMMER. Nucleic Acids Res 1999, 27:4636-464|.

34. HaloLex [http://www.halolex.mpg.de] 
35. Falb M, Pfeiffer F, Palm P, Rodewald K, Hickmann V, Tittor J, Oesterhelt $D$ : Living with two extremes: conclusions from the genome sequence of Natronomonas pharaonis. Genome Res 2005, I 5: 1336-1343.

36. Lowe TM, Eddy SR: tRNAscan-SE: a program for improved detection of transfer RNA genes in genomic sequence. Nucleic Acids Res 1997, 25:955-964.

37. Altschul SF, Madden TL, Schaffer AA, Zhang J, Zhang Z, Miller W, Lipman DJ: Gapped BLAST and PSI-BLAST: a new generation of protein database search programs. Nucleic Acids Res 1997, 25:3389-3402.

38. Microbial Genome Analysis System package MiGenAS [http://www.migenas.org]

39. Rampp M, Soddemann T: A work flow engine for microbial genome research. In Forschung und wissenschaftliches Rechnen 2005 Edited by: Kremer K and Macho V. Goettingen, Germany, Gesellschaft f. wiss. Datenverarbeitung (GWDG); 2005.

40. MEGA3 phylogenetic tool software package [http:// www.megasoftware.net]

41. Kumar S, Tamura K, Nei M: MEGA3: Integrated software for Molecular Evolutionary Genetics Analysis and sequence alignment. Brief Bioinform 2004, 5: I50-163.

42. Robinson NP, Dionne I, Lundgren M, Marsh VL, Bernander R, Bell SD: Identification of two origins of replication in the single chromosome of the archaeon Sulfolobus solfataricus. Cell 2004, I 1 6:25-38.

Publish with Bio Med Central and every scientist can read your work free of charge

"BioMed Central will be the most significant development for disseminating the results of biomedical research in our lifetime. "

Sir Paul Nurse, Cancer Research UK

Your research papers will be:

- available free of charge to the entire biomedical community

- peer reviewed and published immediately upon acceptance

- cited in PubMed and archived on PubMed Central

- yours - you keep the copyright

Submit your manuscript here:

http://www.biomedcentral.com/info/publishing_adv.asp
BiolMedcentral 